\title{
A model of functional recovery after significant loss of neural tissue: biofeedback based healing of vestibular dysfunction
}

\author{
Florian Jug ${ }^{*}$, Christoph Krautz, Angelika Steger \\ From Nineteenth Annual Computational Neuroscience Meeting: CNS*2010 \\ San Antonio, TX, USA. 24-30 July 2010
}

Vestibular dysfunction can significantly affect balance, posture, and gait. Hundreds of patients suffering from significant loss of neural (vestibular) tissue were helped with a new treatment using biofeedback - a strip of electrodes feeding head-tilt information onto the tongue surface $[1,2]$. The success rate is stunning but the neural processes associated with this treatment are, to date, not understood in detail.

We present a model that can explain how a minor fraction of remaining vestibular tissue, trained using biofeedback, regains the ability to balance the modeled organism in an upright position.

\section{Methods}

Our model contains 4 populations of rate-coded units with sigmoid activation functions that are either not or fully connected via activity modulated Hebbian synapses (see Figure 1). A vestibular apparatus (VA) senses the tilt level of the modeled organism. VA is connected to a hidden population (HL) connected to a motor control population (BA), generating balancing actions and thereby closing a control loop by influencing the current tilt level. A second loop, the biofeedback, contains a population mimicking the signal of the mentioned tongue strip (TS).

VA and TS create population-coded output because their units are broadly tuned to different preferred tilt levels. HL and BA use winner take all dynamics. All units receive, in addition to the afferent input, a constant amount of white noise. Feedback connections from BA to HL force these populations to commit to a common, converged state.

\footnotetext{
* Correspondence: florian.jug@inf.ethz.ch

Institute of Theoretical Computer Science, ETH Zurich, Zurich, Switzerland
}

Destroyed VA-units reduce the total input to HL. Homeostatic input normalization iteratively strengthens remaining postsynaptic processes to regain the desired input strength.

\section{Results}

After destruction of a significant amount of VA-nodes $(>90 \%)$ the remaining efferent signal does not exceed HL's noise level and the entire system turns nonfunctional. During homeostatic input normalization the tuning of remaining efferent VA connections broadens and causes the system to settle in a non-functional state.

Biofeedback substitutes missing vestibular data and re-enables BA to generate sensible actions. BA-HL-

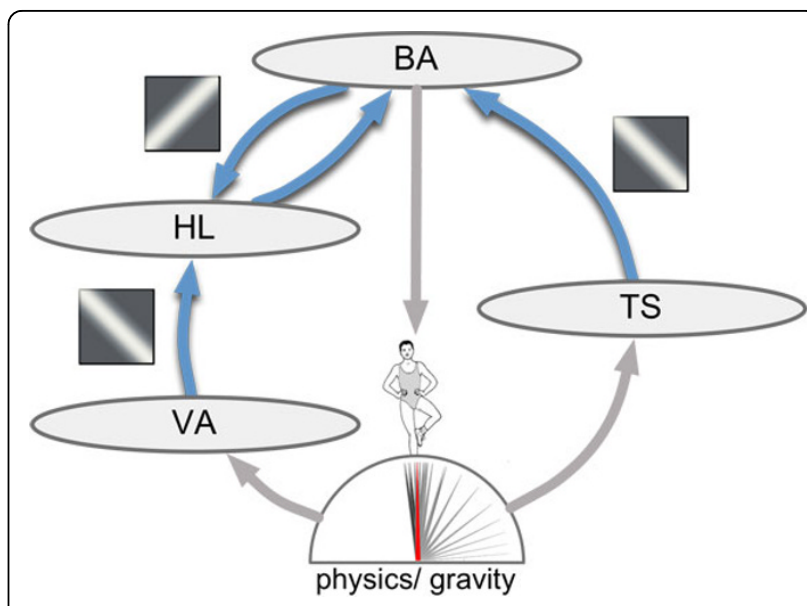

Figure 1 Model architecture. Ellipses: populations; blue (darker) arrows: directed, full connectivity; gray arrows: causal dependencies, i.e., sensing or acting. Abbreviations are explained in the text. Quadratic insets show the initial weight matrices, white coding for high values. 
feedback forces HL's output to be correlated with the sensed tilt angles. Thus, activity modulated Hebbian learning re-sharpens VA's efferent tuning and the modeled organism relearns to balance in an upright position - even without biofeedback. Phenomenologically this effect is also observed in human patients.

\section{Acknowledgements}

The authors would like to thank ETH Research Grant ETH-23 08-1.

Published: 20 July 2010

\section{References}

1. Tyler M, Danilov YP, Bach-Y-Rita P: Closing an open-loop control system: vestibular substitution through the tongue. J Integr Neurosci 2003, 2(2):159-164.

2. Danilov YP, Tyler ME, Skinner KL, Hogle RA, Bach-y-Rita P: Efficacy of electrotactile vestibular substitution in patients with peripheral and central vestibular loss. J Vestib Res 2007, 17(23):119-130.

doi:10.1186/1471-2202-11-S1-P111

Cite this article as: Jug et al:: A model of functional recovery after significant loss of neural tissue: biofeedback based healing of vestibular dysfunction. BMC Neuroscience 2010 11(Suppl 1):P111.

Submit your next manuscript to BioMed Central and take full advantage of:

- Convenient online submission

- Thorough peer review

- No space constraints or color figure charges

- Immediate publication on acceptance

- Inclusion in PubMed, CAS, Scopus and Google Scholar

- Research which is freely available for redistribution

Submit your manuscript at www.biomedcentral.com/submit 